\title{
Retraction Note to: A Cluster-Based Distributed Cooperative Spectrum Sensing Techniques in Cognitive Radio
}

\author{
N. Shwetha, N. Gangadhar, L. Niranjan, and Shivaputra
}

\section{Retraction Note to: Chapter "A Cluster-Based Distributed Cooperative Spectrum Sensing Techniques in Cognitive Radio" in: J. S. Raj et al. (eds.), Innovative Data Communication Technologies and Application, Lecture Notes on Data Engineering and Communications Technologies 59, https://doi.org/10.1007/978-981-15-9651-3_20}

The Volume Editors and authors retract this conference paper [1] because it has substantial overlap with a PhD thesis by a different author [2].

N. Shwetha, N. Gangadhar, and Shivaputra agree to this retraction; L. Niranjan has not responded to any correspondence from the publisher about this retraction.

[1] Shwetha N., Gangadhar N., Niranjan L., Shivaputra (2021) A Cluster-Based Distributed Cooperative Spectrum Sensing Techniques in Cognitive Radio. In: Raj J.S., Iliyasu A.M., Bestak R., Baig Z.A. (eds) Innovative Data Communication Technologies and Application. Lecture Notes on Data Engineering and Communications Technologies, vol 59. Springer, Singapore. https://doi.org/10.1007/978-98115-9651-3_20

[2] Babu G., (2019) Analysis and Evaluation of Distributed Cooperative Spectrum Sensing Techniques in Cognitive Radio Sensor Networks, St. Peter s Institute of Higher Education and Research; 2019 http://hdl.handle.net/10603/280064

The retracted version of this chapter can be found at https://doi.org/10.1007/978-981-15-9651-3_20 